\title{
Bucareli en el debate histórico
}

\author{
Álvaro Matute Aguirre
}

IIH-UNAM

$\mathbf{P}$ ocos temas históricos dividen opiniones y apasionan tanto code su conclusión, han generado una grandísima cantidad de ataques y defensas, principalmente en la prensa y posteriormente en libros que han ido formando una historiografia nada escasa y muy cargada de intencionalidad política. Bucareli es uno de los grandes temas de la historia de las relaciones entre México y Estados Unidos, no tanto por lo que hayan sido los tratados en sí como por lo que se ha dicho de ellos. Conviene traer a colación aquí dos ideas complementarias: la de G. M. Young, que recientemente ha puesto en circulación David Brading: "El verdadero tema central de la historia no es lo que ocurrió, sino lo que la gente sintió acerca de ello cuando estaba ocurriendo", 1 que es semejante a lo que antes habría expresado Maitland: "Lo esencial en la historia no es lo que sucedió, sino lo que la gente pensó o dijo sobre ello. ${ }^{22}$ Es preciso matizar estas dos afirmaciones. Ambos historiadores se basan en la inmediatez de lo que sucedió para permitir que el historiador en otros tiempos recoja de ello lo que la gente sintió, dijo o pensó. Me permito agregar, con la perspectiva del historicismo, que prefiero utilizar un tiempo compuesto y no uno

1 Young, Victorian England. Portrait of an Age, citado por Brading, Orbe, 1991, p. 13.

2 Citado por Jones, Extraño, 1966, p. vII. 
simple. Prefiero decir "ha pensado, ha dicho, ha sentido", en lugar del pretérito a secas. Porque finalmente esos dichos, pensamientos o sentimientos también tienen historicidad y, si son recurrentes, es que su vitalidad no se ha perdido y continúa afectando a la gente que se expresa en torno a hechos ocurridos en el pasado.

Bucareli es uno de esos hechos que se aparecen en la conciencia histórica mexicana de manera recurrente y que no son solamente asunto de académicos. Nunca demoran mucho los políticos activos o retirados, o simples ciudadanos, en publicar alguna opinión o dato histórico en las páginas de los diarios. Son de esos hechos que han alcanzado la interesante dimensión de mito fundamental en la historia del siglo $\mathrm{xx}$ y que se emparentan con otro asunto concreto de profunda controversia: el Tratado McLane-Ocampo. Por lo pronto no me atrevo a señalar cuál de los dos ha generado más utilización de tin ta. Podría suponer que el decimonónico, por preceder en casi tres cuartos de siglo al sucedido en el número 85 de la calle de Bucareli a partir del 14 de mayo de 1923. Sin embargo, no le iría muy a la zaga.

Volviendo al punto de partida, me parece importante rescatar no sólo lo que en su momento se expresó en torno a los convenios, tratados o conversaciones de Bucareli, sino lo que se ha seguido diciendo a través de los años; tanto, que por lo pronto no cabe en una sola ponencia. En esta ocasión me limitaré a dar una apreciación general del problema y de particularizar lo que considero puntos esenciales de la con. frontación de opiniones.
II

Son tres los grupos de autores que se han ocupado del problema, de 1923 a la fecha. En primer lugar, están los protagonistas y coetáneos, cuya intencionalidad es significativa en la medida en que se trata de quienes quieren justificar o atacar el asunto en virtud de una gran carga de intereses.

La segunda generación es la de aquellos que sin haber sido protago. nistas o coetáneos, vivían cuando ocurrieron los hechos pero que por su juventud no se incorporaban aún al quehacer político o intelectual. Ésta es la intermedia entre los protagonistas y la tercera generación, formada por quienes no vivieron los hechos y que se han referido a ellos con base solamente en la memoria histórica, bibliográfica, hemerográfica y documental.

Cabe aquí hacer una diferenciación importante entre las tres. Los primeros -protagonistas-, estuvieron involucrados en los hechos, ya sea como partícipes directos o como espectadores activos que se manifiestan como parte de la opinión pública. En ellos las expresiones ideológicas son más aceptadas en la medida en que se trata de responsables de los hechos ante la historia. Temen ser juzgados $\mathrm{y}$, desde luego, condenados.

La tercera generación, en su mayoría, es la de los académicos. Es decir, la de aquellos que se han ocupado y se ocupan de los hechos por interés histórico como parte de sus investigaciones sobre el tema en particular o sobre asuntos más amplios de los que el aludido forma parte. Si bien no se excluye que expresen intereses, preferencias 
o actitudes políticas, su base radica en seguir las reglas del juego académico.

Queda entre ambas la generación intermedia. Son aquéllos, como ya expresé, personas jóvenes para ser protagonistas y algo mayores para ser sola. mente académicos. Se trata de los primeros que quisieron hacer la reconstrucción histórica indirecta de los hechos, pero que, por encontrarse no lejos de ellos, la carga política no sólo es muy grande sino que a veces puede ser tan grande o mayor que la de los coetáneos. Participa de lo académico porque a diferencia de los primeros no es la memoria el principal elemento reconstructivo, sino los documentos disponibles encontrados, los que dan base a sus afirmaciones.
Resulta de interés pulsar estás opiniones, tratando de seguir el espíritu de Young y Maitland, para recrear un proceso que, pese a la desaparición física de la generación protagonista, sigue levantando ámpula ante la opinión pública mexicana.

Una aclaración fundamental es que, por tratarse de un convenio bilateral, hay historiografia mexicana y norteamericana. Si bien existen estudios norteamericanos muy sólidos que ven el problema desde el ángulo de los archivos de Washington, por lo pronto este estudio se limita al material mexicano por las repercusiones que lleva implícitas en la opinión pública, ya que tengo la impresión, espero que fundada, de que mientras en México se trata de

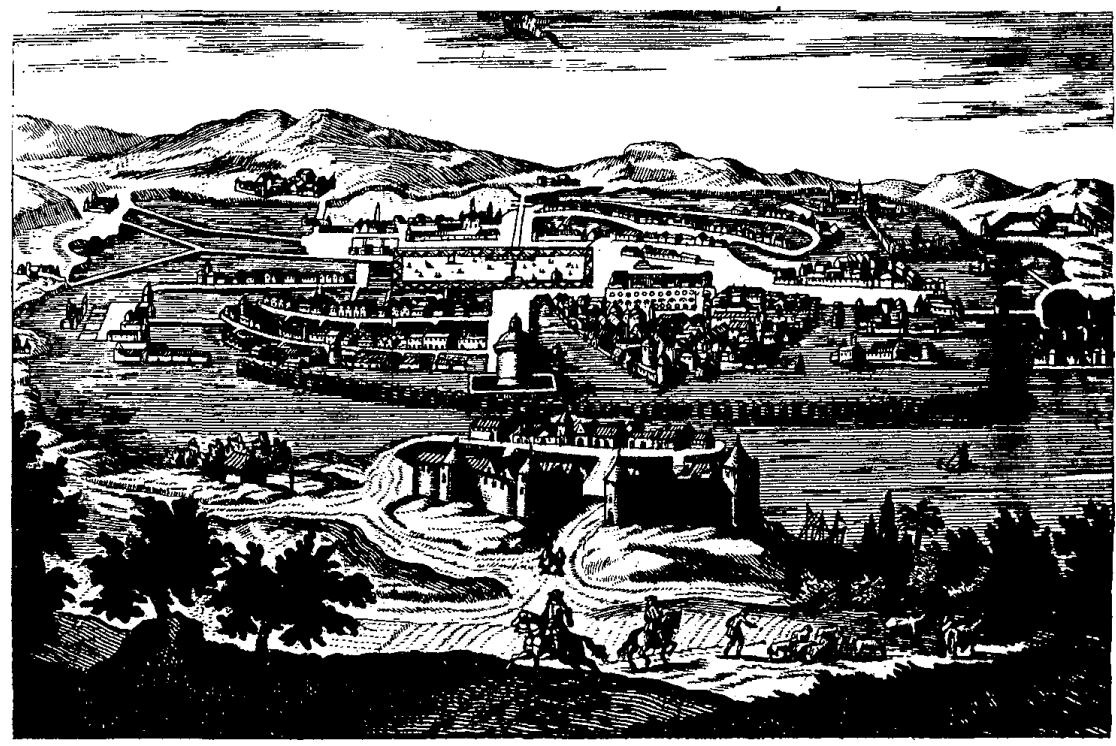


un asunto vital que trasciende hacia la opinión pública, en Estados Unidos el asunto al parecer permanece en la esfera académica. No obstante lo anterior, en un plazo no muy largo, me gustaría ofrecer el proceso completo, siguiendo la bibliografia de ambos países.

III

Por el lado mexicano, el problema de Bucareli generó controversia desde el momento de su gestación. Las páginas de los principales diarios recogieron expresiones de testigos activos del acontecer. Ciertamente se trataba de personas adversas al gobierno en turno, presidido por el general Álvaro Obregón, como los licenciados Luis Cabrera y Salvador Diego Fernández o el ingeniero Vito Alessio Robles. Ellos provocaron la respuesta inmediata de los personeros del régimen, e incluso de participantes en las pláticas, como el licenciado Fernando González Roa. Ello para no entrar en debates camerales que terminaron de manera violen. ta, como fue el caso del asesinato del senador por Campeche Francisco Field Jurado, que se opuso a los convenios.

La circunstancia de que, una vez logrado el reconocimiento del gobierno mexicano por el de la Casa Blanca - comunicado de manera jubilosa por Obregón en su informe de 1 de sep. tiembre de 1923-, se complicara con la vacante de Adolfo de la Huerta en la Secretaría de Hacienda y con la negativa a reconocer el triunfo electoral de Jorge Prieto Laurens en San Luis Poto- sí, fue aprovechada por los nuevos desplazados del gobierno para alegar en su favor que se habían separado de Obregón porque no estaban de acuerdo con lo acordado en dichos convenios.

El hecho de que una figura de altura política mayor como De la Huerta se atreviera a enfrentarse al gobierno de su paisano y ex amigo Obregón, fue el acicate para que muchos enemigos del régimen y del gobierno se unificaran en una empresa militar de proporciones serias que duraría prácticamente el primer semestre de 1924. La rebelión delahuertista, originada por cuestiones electorales -federal y local- se fue envolviendo en una ideología nacionalista reivindicativa de la soberanía ultrajada por el alto precio pagado por Obregón al reconocimiento norteamericano. Se trató de convencer a la opinión pública de que De la Huerta se levantaba porque Obregón y su virtual heredero Calles habían conculcado la soberanía al aceptar condiciones humillantes para la Constitución del país y su marco generador, la revolución mexicana.

De ese modo, fueron convergiendo dentro del delahuertismo muchos de los argumentos contrarios al gobierno. Eso ciertamente facilitó algunas defensas, dado que podría ser dudoso que don Adolfo se hubiera rebelado por su patriotismo antibucareliano. Sin embargo, hubo quienes practicaron el deslinde adecuado y se centraron en el punto del significado de los tratados.

El problema nació en medio de una crisis política que desembocó en una confrontación militar. No es gratuita, 
pues, la ideología que desarrollaron los delahuertistas por varias razones: en primer lugar, aprovecharon el descontento ocasionado por lo que cedió el gobierno mexicano ante las presiones norteamericanas; en segundo lugar, la viril protesta de Vito Alessio Ro. bles por el asesinato de Field Jurado se dio en el momento propicio. Por otra parte, el cierre de frontera para adquisición de armamentos por parte de los rebeldes y la actitud de Estados Unidos favorable para el gobierno, fueron vistas como "pago" por lo convenido en Bucareli. ${ }^{3}$

No faltaron las respuestas oficiales. Durante el año de 1924, ante las opiniones de antiguos carrancistas como Luis Cabrera, Fernando González Roa publicó cinco artículos en El Universal $^{4}$ en los que negó que Estados Unidos hubiera impuesto su criterio y comentó que no se dio marcha atrás en la legislación mexicana. Por su parte, el binomio Alberto J. Pani-Aarón Sáenz, secretarios de Relaciones Exteriores de Obregón antes e inmediatamente después del reconocimiento norteamericano, ${ }^{5}$ publicaron bajo el sello oficial de la Secretaría de Relaciones Exteriores, el libro La cuestión internacional mexicano-americana durante el gobierno del general Álvaro Obregón, que re-

3 Para ilustrar el caso, véase Trujillo, Adolfo, 1966. En esta obra se ofrecen todos estos elementos.

4 Del 9 al 14 de febrero. Después, el 5 de febrero de 1925 refutó al general Cándido Aguilar.

5 Por si hace falta aclararlo, Pani dejó la Secretaría de Relaciones Exteriores para asumir la titularidad de Hacienda cuando renunció De la Huerta. Sáenz, subsecretario hasta entonces, sucedió a Pani en septiembre de 1923. coge los proyectos del Tratado de Amistad y Comercio y de Convención de Reclamaciones propuestos por el Departamento de Estado Norteamericano (Charles E. Hughes), así como las contrapropuestas de la cancillería mexicana. Siguen las minutas de las "conferencias internacionales mexicanoamericanas de 1923", que es el nombre reconocido de las conversaciones de Bucareli y, finalmente, los resultados, es decir, los textos aprobados para las convenciones particular y general de las Convenciones de Reclamaciones. ${ }^{6} \mathrm{El}$ libro es útil a la causa obregonista en la medida en que se defiende gracias a que las pretensiones norteamericanas eran avasalladoras y lo negociado resultó más favorable para México.

Dentro del ámbito oficial se llegó a negar, incluso, el hecho de que existieran los Tratados de Bucareli en la medida en que ningún documento oficial es llamado así; pero, sobre todo, el punto crítico, señalado desde el principio por Luis Cabrera, sobre la aceptación de la no retroactividad de la aplicación del artículo 27 por parte de México, fue debatido por los obregonistas desde los más exquisitos recovecos jurídicos.

Ahora bien, el debate de Bucareli por parte de sus protagonistas y coetá-

6 Este libro, publicado en 1924 y reimpreso en 1926, fue calificado por Vito Alessio Robles como "joya bibliográfica". Excélsior, 24 de junio de 1937. El libro en cuestión es recuperado dentro del posterior de Aarón Sáenz, Política, 1961. Forma el apéndice I, pp. 249-446. Agrega un apéndice II con correspondencia oficial intercambiada por los dos gobiernos en torno al artículo 27. 
neos no se agota en los años inmediatos posteriores a la celebración de las conversaciones y firma de las convenciones, sino que sigue vigente casi hasta el momento de la extinción física de esa generación. Había momentos en que las aguas se agitaban de nuevo y permanecieron así por un buen tiem. po; dos momentos surgieron durante el gobierno de Lázaro Cárdenas y en la transición entre el de Ruiz Cortínez y el de López Mateos, esto es, hacia 1936-38 y veinte años después, en el bienio 1956-58. La fuerte revisión de la revolución mexicana que tuvo lugar en los años treinta casi no dejó de tocar ningún aspecto que implicara claudicaciones, alteraciones o desviaciones, y la política exterior de Obregón daba buen material a los primeros revisionistas.

Por ese tiempo aparecen trabajos como los del subsecretario carrancista de Relaciones Exteriores, Salvador Diego Fernández ${ }^{7}$ y el de Vito Alessio Robles. ${ }^{8}$ Se trata claramente de representantes de diferentes opositores al obregonismo, que no podían ocultar sus opiniones, ya sea jurídicas ya sea políticas, sobre las implicaciones de los llamados Tratados de Bucareli. En ese tiempo, incluso, todavía era una posición ideológica por parte de los opositores, llamarlos así, ya que el punto de vista de los herederos del régimen pretendia desterrar ese nombre para así conseguir que la opinión pública olvidara los hechos.

Si bien dentro de ese contexto sur-

7 Pactos, 1937.

8 Tratados, 1937, recogido en una nueva edición en Biblioteca Porrúa.

gió el libro más interesante que se ha producido al respecto, el de Antonio Gómez Robledo, el cual, a su vez, propició la respuesta más cabalmente oficial, la de Manuel González Ramírez, prefiero tratarlos más adelante y continuar con la generación protagónica.

Cabe señalar que dentro del campo defensor hubo polemistas ponderados y juiciosos como los licenciados Fernando Iglesias Calderón, obregonista destacado, y el impecable escritor Genaro Fernández MacGregor, que de manera extraña no compartía puntos de vista con su amigo y congénere ateneísta Isidro Fabela. Mientras la obra de los dos mencionados en primer término permaneció sólo en los diarios, el ataque del colaborador internacionalista de Carranza apareció en forma de libro y con el aval de tratarse de un exégesis de La política internacional del presidente Cárdenas. ${ }^{9}$ Conviene, para mejor comprensión, citar el primer párrafo del capítulo dedicado a Obregón:

Para estimar en su gran valor histórico la obra llevada a cabo por el presidente Lázaro Cárdenas, conviene establecer las dos situaciones creadas en materia del petróleo; primero por don Venustiano Carranza y los constituyentes de Querétaro, tal como ha sido desarrollado a grandes trazos en el capítulo anterior; y segundo, la labornegativa realizada por el gobierno del Gral. Obregón, como una consecuencia de las conferencias de Bucareli. 10

${ }^{9}$ Apareció en Problemas Agrícolas e Indus. triales de México, vol. vI, núm. 4, octubre-diciembre 1953, pp. 3-116.

10 Fabela, "Política", 1953. Las cursivas son mías. 
Era costumbre de la revista en que apareció el texto de Fabela, dirigida por Manuel Marcué Pardiñas, publicar trabajos de réplica a otros allí publicados, por lo que al final del mismo número está un artículo largo de Manuel González Ramírez, "La política exterior del presidente Obregón"."1 De nuevo la defensa a ultranza contra lo asentado por don Isidro.

En los años cincuenta apareció el libro de Roberto Guzmán Esparza, Memorias de don Adolfo de la Huerta, a raíz de la muerte del ex presidente sonorense. Ahí venían acusaciones fuertes contra el círculo obregonista y que propiciaron la intervención de uno de los grandes protagonistas que habían permanecido en silencio: Aarón Sáenz, ${ }^{12}$ ya que Alberto J. Pani nunca había rehuido el problema. ${ }^{13}$ Nuevamente surgió el encuentro entre delahuertistas contra obregonistas, reforzado por el voluminoso libro de Adolfo Manero Sánchez y José Paniagua Arredondo. 14

Sáenz trató de poner un punto final y en cierta manera lo hizo. No porque su libro diga la "última palabra" sobre

11 González Ramírez, "Política", 1953, pp. $400-412$.

12 Por lo que respecta a Guzmán Esparza, antes de aparecer como libro, las Memorias de De la Huerta fueron publicadas en entregas por el diario Excélsior, en marzo y abril de 1958. Al mismo tiempo salían las réplicas de Sáenz, que fueron recogidas en Política, 1961.

13 Por lo que respecta a Pani, en sus distintas autobiografias tocó el tema. Muy levemente en Contribución, 1936, y en Apuntes, 1945. (Agradezco a Paz Pani el obsequio de este ejemplar.) Donde sí entró en materia fue en el monográfico Conferenctas, 1953.

14 Manero Sánchez y Paniagua Arredondo, Traicton, 1958. el asunto, ya que ninguno puede aspirar a ello, sino en cierta manera, porque, hasta donde tengo recogido, no hay bibliografia posterior, aunque la hemerografia sigue siempre contribuyendo al debate, si bien por una parte sobreviene la extinción de la generación actuante y, por otra, la generación siguiente abandonaba el tratamiento monográfico, aunque el tema aparece en historias generales de la revo. lución o en obras de amplia cobertura temporal en las que el asunto resultaba insoslayable. Pero hay un punto muy rescatable en el libro de Sáenz que quiero destacar y es su metodología. Además de dedicar más de la mitad de las páginas a reimprimir el viejo libro de 1924-26, la parte escrita por él es abiertamente polémica contra todo lo que se había escrito desde el principio, es decir desde Luis Cabrera en adelante. Lo lamentable es su tipo de respuesta a cada cuestionamien. to y la falta de sistematización de los diferentes argumentos. Trata de descalificar a su enemigo al ubicarlo en el bando político al que perteneció. Esto conduce a señalar que aquel que no fue obregonista no podía opinar objetivamente sobre el caso. Así, los carrancistas, los delahuertistas, los católicos, etc., están descalificados, por lo que el lector puede sospechar que sólo los obregonistas pueden tener una opinión favorable sobre el tema.

Hay puntos que "resuelve" de manera muy curiosa. Por ejemplo, el asesinato de Francisco Field Jurado. Para "rebatir" el hecho de que pagó con la vida su oposición a la lectura de las convenciones, Sáenz cita el texto en el que Obregón recrimina a Luis N. Mo- 
rones los excesos cometidos. Es decir, que Sáenz descarga en el líder obrero toda la culpabilidad, así como la actuación independiente a la máxima voluntad, y rescata a Obregón con una de esas manifestaciones de teatralidad que montaba para "demostrar" públicamente su condena a un hecho violento. (Hizo lo mismo en el Hotel St. Francis cuando recibió la noticia de la muerte de Carranza.) El hecho es que se salta a la torera el caso del senador campechano.

En otros terrenos, cuando trata de responder a los cargos de traición a la patria que muchos de los comentaristas adversos le endosan a Obregón y su equipo, acude al código penal de 1871 en el que se tipifica el cargo, y a la ley que Juárez había expedido sobre el particulary, como lo hecho en 1923 no cabe dentro de esa tipificación jurídica, no se puede hablar de traición a la patria en relación con la marcha atrás del artículo 27, que implicaron las con. ferencias de Bucareli. La chicanería jurídica no puede ser aceptada por la conciencia histórica.

IV

La década de los treinta se cierra con los dos libros que ejemplifican mejor lo que ha sido el debate en torno a Bucareli: el de Antonio Gómez Robledo y el de Manuel González Ramírez. ${ }^{15}$

15 Las fichas son: Gómez Robledo, Convenios, 1938 (Agradezco a Marianela Heredia, bibliotecaria del Instituto de Investigaciones Históricas de la UNAM, sus esfuerzos para conseguirme un ejemplar). Hay una 2a. edición en inglés, publicada por la uNam en 1940. El de González Ramírez es Llamados, 1939.
El segundo es consecuencia del primero, ya que está encaminado a refutarlo, casi línea por línea. Representan ambos las dos posiciones antagónicas, sin haber sido partícipes de los hechos. La presentación de los autores nos obliga a elaborar una breve semblanza de cada uno.

Antonio Gómez Robledo nació en Guadalajara en 1908. En su ciudad natal obtuvo la licenciatura en Derecho en el año de 1932, pero hay evidencia de que estudió en la Escuela Libre de Derecho de la ciudad de México, ya que él mismo dice que

alrededor del año de $1930 \multimap 0$ muy poco después-me sentaba yo, entre los alumnos de la Escuela Libre de Derecho, en los escaños de la cátedra de historia del derecho patrio que acababa de inaugurar el maestro don Toribio Esquivel Obregón, 16

de quien se asume como discípulo. Esto, en términos de derecho internacional, quiere decir mucho ya que Esquivel Obregón fue uno de los grandes en ese terreno y, de alguna manera, el trabajo sobre Bucareli viene a ser una especie de consecuencia del libro publicado originalmente en 1926 por don Toribio, y al que muchas décadas después Gómez Robledo antepondría un prólogo. Más tarde, don Antonio llegó a obtener el doctorado en filosofía y a destacar, tanto en el internacionalismo como en la filología y filosofía clásicas, pero lo que interesa aquí es rescatar su experiencia de esos años. Fue entonces abogado consultor de la SEP

16 "Prólogo" a Esquivel Obregón, México, 1985, p. 7. 


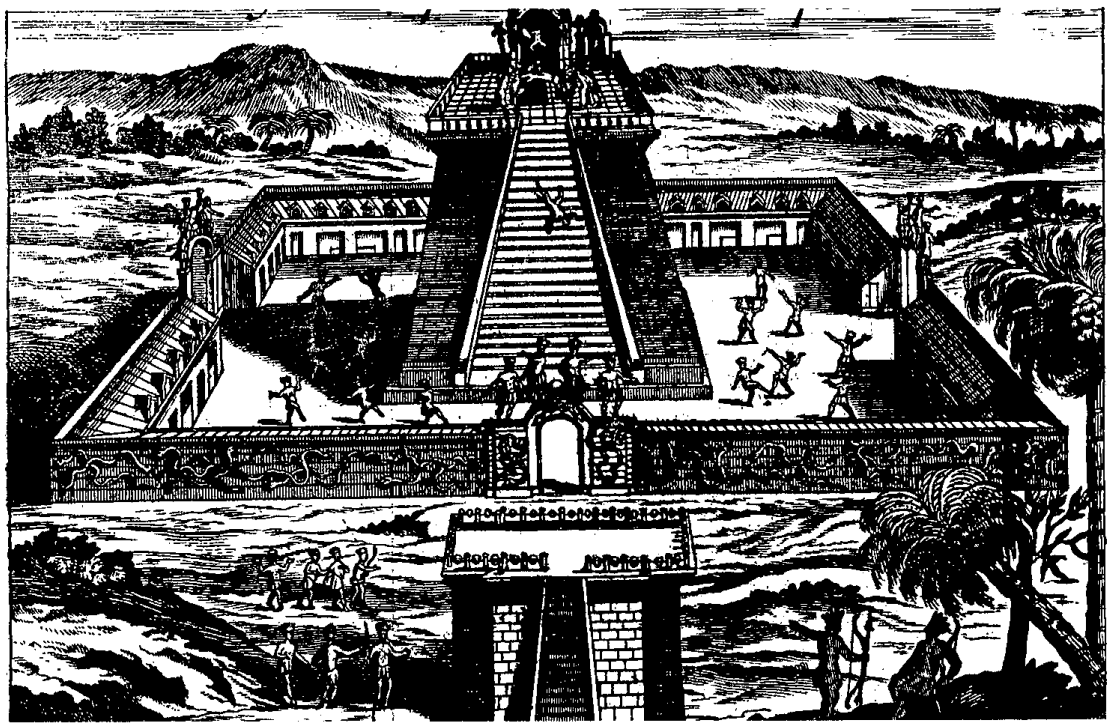

(1935-1938) y de la Comisión Mixta de Reclamaciones entre México y Estados Unidos (1936-1938). Había escrito México en Ginebra (1932) y Anacleto González Flores (1937). ${ }^{17}$ Tratábase, pues, de un joven abogado internacionalista, con una experiencia sólida de trabajo empírico en materia de ele. mentos surgidos precisamente de las convenciones de 1923 , sobre las cuales se dedicó a investigar en medio del ambiente de polémicas anteriormente descrito.

Por su parte, Manuel González Ramírez había nacido en San Juan del Río, Querétaro, en 1904 y estudiado en la Escuela Nacional Preparatoria en

17 Los datos están tomados de Díaz Arciniega, Premio, 1991, pp. 283-284. la generación $20 \cdot 24$, es decir fue estudiante en el cuatrienio obregonista, bajo la égida de Vasconcelos como rector y de Vicente Lombardo Toledano como director del plantel, hasta la ruptura entre los mencionados, precisamente en 1923, cuando la inminencia de la sucesión presidencial comenzó a alterar el orden obregonista. Formó parte en la preparatoria del grupo de "Los Cachuchas", con Alejandro Gómez Arias, Frida Kahlo, Miguel N. Lira y otros. Fuera de ese grupo, perteneció a la misma generación Miguel Alemán. ${ }^{18}$ Aunque lo supongo egresado de la UNAM, el libro que me ocupa tiene una dedicatoria: "Homenaje a la Escue. 1982.

18 Véase González Ramírez, Recuerdos, 
la Libre de Derecho en el XXV aniversario de su fundación", lo cual permitiría suponer que en ella estudió su carrera. De 1926 a 1929 fue abogado de la Secretaría de Relaciones Exteriores, donde colaboró en la Comisión de Reclamaciones de Nueva York, muy cercano al propio Plutarco Elías Calles, a Aarón Sáenz, a Fernando Torreblanca y otros personajes destacados del grupo sonorense. Más tarde destacó como historiador, siendo su campo preferencial la revolución mexicana, a cuyo conocimiento aportó mucho, tanto con obra personal, principalmente con La revolución social de México, como con las Fuentes para la historia de la revolución, que publicó con el apoyo del Patronato de la Histo. ria de Sonora, que presidió durante muchos años. Murió en la ciudad de México en 1979, tras haber fungido como jefe de Historia de la Escuela Na. cional Preparatoria.

Esos dos jóvenes abogados, de 30 y 34 años respectivamente, representarían no sólo las dos posiciones ya esbo. zadas, sino, en términos generales, las que la época había formado como herencia del pasado inmediato. González Ramírez expresaba la convicción de que el Estado mexicano era heredero de la revolución y existía una línea de acción ininterrumpida entre el movimiento de 1910-1920 y su presente. Además, la revolución era consecuencia de todo el empuje liberal del siglo $\mathrm{XIX}$, modernizador a la vez que social. A la larga, González Ramírez contribuyó de manera decisiva a la construcción de la ideología oficial del Estado mexicano. Por su parte, Gómez Robledo sintetizaba dos fuentes formativas: un tradicionalismo jalisciense expresado en su texto sobre Anacleto González Flores y un tradicionalismo nacional que fue heredado por Esquivel Obregón, quien tenía su punto de partida en Lucas Alamán. Sin embargo, Gómez Robledo no desconocía la realidad de la revolución mexicana ya que colaboraba con el Estado derivado de ella y defendía los intereses nacionales como abogado de la Comisión de Reclamaciones. Por otra parte, no desatendía el hecho de la defensa de la revolución y de la nación que expresaban revolu. cionarios como Luis Cabrera y Vito Alessio Robles, totalmente ajenos a la tradición alamanista. A diferencia de intelectuales comó su maestro Esquivel Obregón, Salado Álvarez o Carlos Pereyra, él sería un estrecho colaborador del gobierno mexicano, que en 1992 lo nombró embajador emérito, ya que es uno de los internacional istas más destacados que ha producido el país.

Sin embargo, al no ser el Estado mexicano un "bloque monolítico", éste puede permitir dentro suyo la acción de personas, ideologías y perspectivas distintas, aun contrapuestas, como es el caso de estos dos ilustres abogados, que enriquecerían el humanismo y la historiografía de México.

El libro de Antonio Gómez Robledo, hoy en día y desde hace tiempo una joya bibliográfica, lo es no sólo por su rareza sino por su excelencia. Magníficamente escrito, es producto de una profunda meditación jurídica a la que no es ajena ni la filosofia ni la historia. Su arquitectura lo hace partir de los hechos fácticos, sin llegar a la anécdota pero sí aclarando que la opinión pú- 
blica había ideado la existencia de algo así como unos tratados secretos, que además de no existir no tendrían ninguna aplicación. Deja bien establecido que lo que realmente existe son "dos tratados solemnes por los que se instituyeron dos Comisiones Mixtas de Reclamaciones", una que se encargaría de los casos de 1868 a 1910 y otra para el decenio 1910-1920. Lo otro era un

pacto extraoficial entre los jefes del Ejecutivo de ambos estados, por el cual se acordó reconocer los llamados derechos adquiridos sobre el subsuelo petrolífero e indemnizar en efectivo a los norteamericanos por toda expropiación agraria que excediera de cierta extensión. 19

Tras esa aclaración, establece lo que fue el teatro del debate, es decir que tras la Constitución de 1917 el derecho norteamericano consideró confiscatorias algunas medidas establecidas en el artículo 27. Cuando hubo ocasión, es decir a raíz de la rebelión de Agua Prieta, la Casa Blanca condicionó el reconocimiento del gobierno sonorense a que no se aplicaran las nuevas leyes de manera retroactiva. Obregón respondió en 1921 que las pretensiones del Departamento de Estado eran inadmisibles, pero finalmente la diplomacia se impuso y se dieron las conversaciones entre Fernando González Roa y Ramón Ross con Charles B. Warren y John B. Payne en la referida casa 85 de la calle de Bucareli. "El derecho abolido por los convenios" es el título del segundo capítulo, dividido en dos partes: una re-

19 Gómez Robledo, Convenios, 1938, p. xI. ferida al petróleo y la otra al agro. Más adelante viene el examen de los convenios en materia petrolera, agraria, por lo que se refiere al pacto extraoficial; en seguida trata las dos convenciones, la especial y la general. Concluye con una reflexión sobre la doctrina Monroe y los Convenios de Bucareli, en la que se siente la enseñanza de Esquivel Obregón, más los conocimientos acumulados por el propio autor. Un epílogo escrito después de la expropiación petrolera eleva las ideas de Gómez Robledo del plano jurídico al filosófico, muy en el espíritu de la época.

En cuanto al fundamento central, esto es, el análisis jurídico de la cuestión, queda evidente que los representantes de Obregón aceptaron en 1923 la no retroactividad del artículo 27 en materias agraria y petrolera para satisfacer así las presiones de los representantes de Calvin Coolidge.

En suma, los convenios consistieron en que, a través del pacto extraoficial, el poder ejecutivo se obligó a no dar efecto retroactivo al artículo 27 constitucional en materia de petróleo $\mathrm{y}$ a indemnizar en efectivo a los norteamericanos por toda expropiación agraria que tuviera otro objeto que la dotación ejidal o que, persiguiendo ese fin, excediera de 1755 hectáreas. Aparte se signaron dos tratados solem. nes, aprobados por el Senado, que crearon las dos convenciones ya mencionadas: la especial, para el decenio $1910-1920$, y la general, para 1868 . 1927, con excepción de los diez años de lucha revolucionaria. El pacto extraoficial, en palabras de Gómez Robledo, "es violatorio de la Constitución mexicana, cuyo artículo 27 [...] 
no autoriza a las leyes orgánicas a reconocer los supuestos derechos adquiridos y crear las llamadas concesiones confirmatorias". La manera como expresa Gómez Robledo los resultados debe ser transcrita en su totalidad:

La economía nos ha dicho que dos de los propósitos primordiales de nuestra revolución, la justicia social en la distribución de la tierra y la reivindicación para el Estado de su patrimonio secular sobre el subsuelo hidrocarburado, han quedado burlados por los pactos de 1923 . Y con ellos, la paz orgánica que sólo vendrá por la justicia en el agro y la inde. pendencia económica del país, que hoy se vincula al dominio estatal de ciertas riquezas naturales. ${ }^{20}$

Compara, en consecuencia de los derechos adquiridos en 1923, a los norteamericanos con el civis romanus del continente y a "nosotros" con los populi foederati, los reges socit. Análisis magistral, se convirtió de in. mediato en un libro inómodo. Reque. ría de una respuesta fuerte que no deslegitimara al régimen de su compromiso revolucionario. Ello estaría listo de ma. nera inmediata, en enero de 1939 , y el autor sería el también abogado Manuel González Ramírez. ${ }^{21}$

En términos muy generales, González Ramírez aprovecha el avasallamiento norteamericano a la América Latina, lo que había leído en Carlos Pereyra, ${ }^{22}$ para presentar a un gobier-

20 Ibid., p. 206.

21 Se supone que el libro ya estaba escrito cuando apareció el de Gómez Robledo. Tal vez a ello se deba que la polémica contra él aparezca siempre en las notas a pie de página.

${ }^{22}$ De quien elaborará más tarde una antología. no mexicano consciente de su debilidad, pero como hábil y patriótico negociador que impidió que los norteamericanos se salieran enteramente con la suya. Digamos que, en términos históricos, la arrogancia de las administraciones republicanas de los años veinte no conocía límites y ello obliga. ba a la diplomacia de los débiles a utilizar todo su ingenio, pero González Ra. mírez no llama la atención sobre un hecho fundamental: la necesidad ob. sesiva del gobierno de Obregón a ser reconocido. En cambio, el abogado entra en acción para llegar a conclusiones sorprendentes a través de las cuales quiere convencer a los lectores de la sinrazón de aquellos que acusan al gobierno de Obregón de haber dado marcha atrás en Bucareli. Arguye que no fue anti ni inconstitucional la no retroactividad del artículo 27 , exactamente en los mismos términos que años después expresaría Aarón Sáenz. La retórica, en su sentido peyorativo, entra en su auxilio para hacer malabarismos aprovechando el hecho de la expropiación petrolera, para demostrar con él que a la larga las conferencias de 1923 no fueron un obstáculo para la conquista de los derechos del pueblo mexicano y su patrimonio.

González Ramírez representa la oficialidad a ultranza y no sólo la defensa de Obregón. Y aquí cabe aclarar que Gómez Robledo insiste con frecuencia en que no es el presidente Obregón el blanco de sus ataques, sino la situación general; no es personalista la motivación del libro, sino algo de alcance mucho mayor. Si bien González Ramírez fue un constante abogado defensor de la causa sonorense, también tiene 
constantes en su obra que lo hacen trascender esa inmediatez. Es autor de una ardorosa defensa de Melchor Ocampo por los ataques que la memoria del michoacano ha recibido a causa del Tratado con McLane. Más adelante defendió lo indefendible: a Poinsett. Esto tuvo lugar en una reseña al libro de José Fuentes Mares, que lleva el sig. nificativo título de "Punza Poinsett", en la cual apuesta todo en favor del progresismo que viene del norte contra el misoneísmo hispanista que animaba al historiador chihuahuense. No es éste el lugar para hacer estas glosas, pero conviene llamar la atención acerca de cómo se constituye una mentalidad condicionada por la historia oficial en la cual el Estado y sus intérpretes, los go biernos, siempre tienen la razón aunque se contradigan paso a paso.

V

¿Quién ganó la batalla? Tal vez no ha habido vencedor ni vencido. Podría argüirse que si fue la verdad histórica, el bando representado por Gómez Robledo, no obstante, no deja de haber opiniones como la del embajador $\mathrm{Hu}$. go $B$. Margáin, que alguna vez en carta al diario Excélsior trataba de decir que no había habido Tratados de Bucareli porque ningún documento se llamaba así y lo que hubo fueron conferen. cias. ${ }^{23}$ Es decir, hoy la doctrina oficial

23 "Conferencias de Bucareli. No hubo tratados", Excélsior, 16 de diciembre de 1986. Un par de días después el escritor Nikito Nipongo (Raúl Prieto), refutó de manera sólida a Margáin: "El senador pretende ocultar bajo un truco semántico la felonía obregonista." sigue en vigor y nunca falta alguien dispuesto a defenderla, pese a la utilización de sofismas. Por el lado académico, los historiadores de la nueva generación han visto las cosas con mayor perspectiva y serenidad, pero sin ocultar el hecho de la cesión de privilegios a Estados Unidos, como es el caso de Lorenzo Meyer en su obra acerca del petróleo. $^{24}$

Los acuerdos no constituyeron el "tratado secreto" que a espaldas de la opinión pública renunciaba a las metas nacionalistas de la revolución, como lo han querido hacer aparecer algunos enemigos de Obregón; pero tampoco fueron un inocuo intercambio de impresiones cuyos resultados se apegarian estrictamente a la ketra de la Constitución, como lo han sostenido otros. En la práctica, el gobierno mexicano se vio obligado por las circunstancias a admitir que había que poner un alto -que por el momento pareció definitivo-a los puntos más im. portantes de la reforma petrolera. La re. anudación de las relaciones formales con Washington, después de concluidas las conferencias [...] fue un éxito resonante para su régimen; [...] pero escasamente se puede decir lo mismo en relación al interés nacional tal y como éste fue concebido por las diversas corrientes revolucionarias. 25

En otra obra, Martha Strauss Neuman muestra cuánto gastó el gobierno de Obrègón en propaganda para con. vencer a la opinión pública norteame-

24 Meyer, Conflicto, 1972.

25 Ibid., pp. 208-209. En nota al pie agrega que Obregón dijo la verdad a medias cuando afirmó que el reconocimiento no fue fruto de compromisos ni convenios contrarios a las le. yes. 


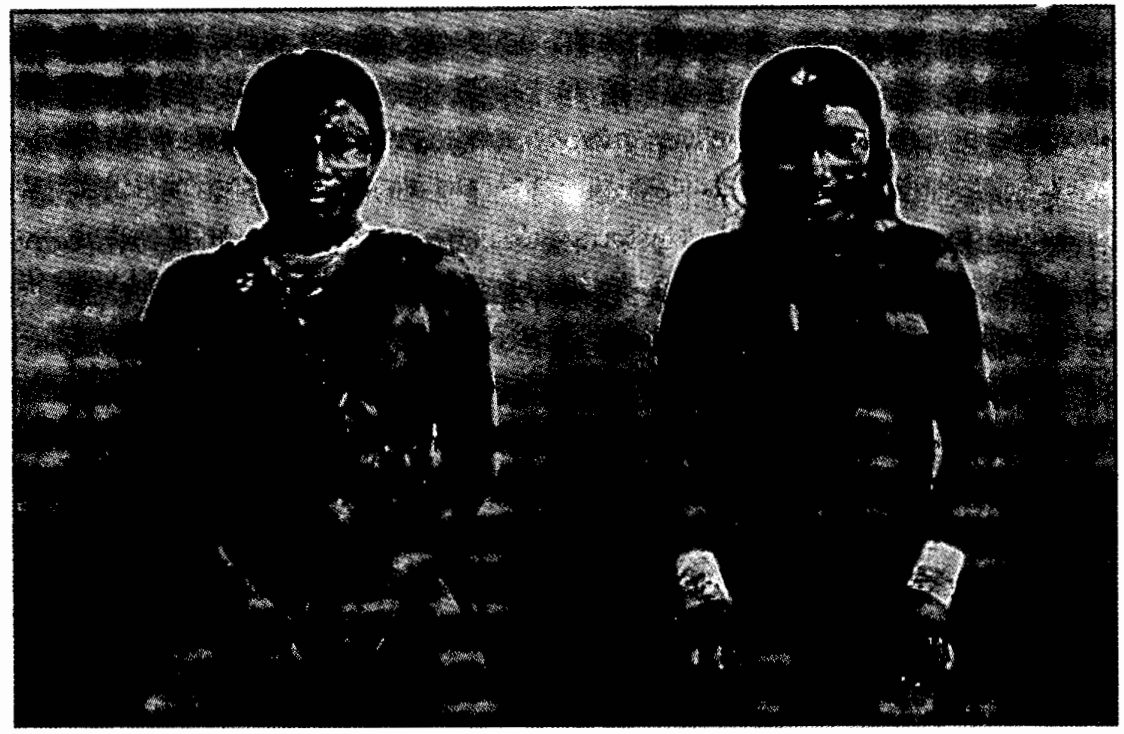

ricana de las bondades de su régimen, el cual debía ser reconocido. ${ }^{26}$ En ese contexto, los argumentos de Sáenz y González Ramírez son insostenibles.

El caso del reconocimiento del gobierno de Obregón ha propiciado que corran muchos litros de tinta y se gasten grandes cantidades de papel, como quedó dicho al principio, incluso más que en el caso del Tratado McLane-Ocampo, aunque tampoco es desdeñable la posibilidad de someter a cotejo las opiniones vertidas en torno a este último. No ofrezco ningún descubrimiento documental novedoso, ni siquiera una opinión nueva. Mi interés radica en rescatar las expresiones originadas por un acto diplomático que

26 Strauss Neuman, Reconocimiento, 1983. esa misma opinión pública consideró de mucha trascendencia para la marcha de la historia nacional. Abogados, periodistas y políticos y más tarde académicos han confirmado que Maitland y Young tienen razón: lo que se ha dicho acerca de lo que pasó, por lo menos, es tan interesante como los hechos mismos, aunque yo sospecho que a veces los sobrepasan.

\section{BIBLIOGR AFÍA}

-Alessio Robles, Vito, Los Tratados de Bucareli, A. del Bosque, México, 1937.

-Brading, David, Orbe indiano. De la monarquía católica a la república criolla, 1492-1867, Fondo de Cultura Económica, México, 1991. 
-Díaz Arciniega, Victor (ed. y comp.), Premio Nacional de Ciencias y Artes (1945-1990), Fondo de Cultura Económica/Secretaría de Educación Pública, 1991.

-Fabela, Isidro, "La política internacional del presidente Cárdenas", Problemas Agrícolas e Industriales de México, vol. vII, núm. 4, octubre-diciembre 1953.

-Fernández, Salvador Diego, Los pactos de Bucareli. El Tratado de la Mesilla, Editorial Polis, México, 1937.

-Gómez Robledo, Antonio, Los Convenios de Bucareli ante el derecho internacional, Editorial Polis, México, 1938.

-González Ramírez, Manuel, Los llamados Tratados de Bucareli. México y los Estados Unidos en las convenciones internacionales de 1923, Ediciones Fábula, México, 1939.

, "La política exterior del presidente Obregón", Problemas Agrícolas e Industriales de México, vol. vi, núm. 4, octubre-diciembre 1953.

, Recuerdos de un preparatoriano de siempre, Universidad Nacional Autónoma de México, México, 1982.

Obregón, México y los Estados Unidos an te el derecho internacional, Secretaría de Relaciones Exteriores, México, 1985.

-Guzmán Esparza, Roberto, Memorias de don Adolfo de la Huerta, según su propio dictado, transcripción y comentarios de..., Ediciones Guzmán, México, 1957.

-Jones, Howard Munford, Este extraño Nuevo Mundo. Años formativos de la cul- tura norteamericana, UTEHA, México, 1966.

-Manero Sánchez, Antonio y José Paniagua Arredondo, Los Tratados de Bucareli. iTraicióny sangre sobre México! Un capítulo del "Libro negro" de las relaciones entre México y los Estados Unidos durante la Revolucion, 2 vols., s. e., México, 1958.

-Meyer, Lorenzo, México y los Estados Unidos en el conflicto petrolero (1917. 1942), El Colegio de México, México, 1972.

-Pani, Alberto J., Mi contribucion al nuevo régimen, 1910-1933, Editorial Cultura, México, 1936.

, Apuntes autobiográficos exclusivamente para mis hijos, edición del autor, México, 1945. , Las Conferencias de Bucareli, Editorial Jus, México, 1953.

-Sáenz, Aarón, La política internacional de la Revolución. Estudios y docu. mentos, prólogo de Manuel González Ramírez, Fondo de Cultura Económica, México, 1961.

-Strauss Neuman, Martha, El reconocimiento de Álvaro Obregón: opinión ame. ricana y propaganda mexicana (1921. 1923), Facultad de Filosofia y Letras/unım, México, 1983.

-Trujillo, Rafael, Adolfo de la Huertay los Tratados de Bucareli, 12a. ed., prólogo de José Vasconcelos, Librería de Manuel Porrúa, México, 1966 (Biblioteca Mexicana, 19). 


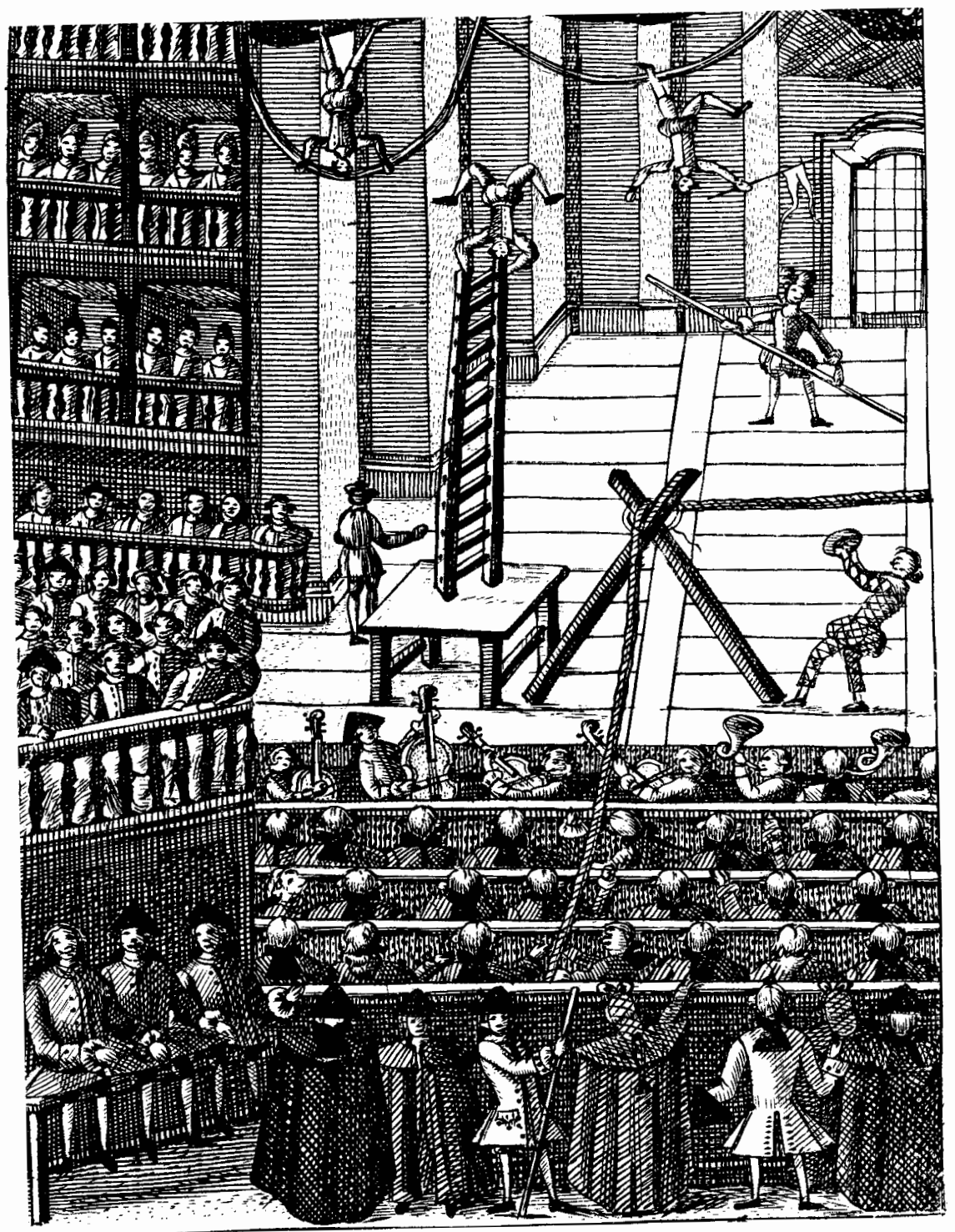

